\title{
Factors Influencing Women's Choice of Place of Delivery in Ngenge Sub-county, Kween District-Uganda
}

\author{
Walwasa John Paul ${ }^{1}$, Ikiriza Antony ${ }^{2,}$, Maureen Andinda ${ }^{2}$ \\ ${ }^{1}$ The International Rescue Committee (IRC), 7 Lower East Road Naguru, Kampala, Uganda \\ ${ }^{2}$ Department of Public Health, School of Health Sciences, Mountains of the Moon University, Fort Portal, Uganda
}

Email address:

iantony2011@gmail.com (I. Antony)

${ }^{*}$ Corresponding author

\section{To cite this article:}

Walwasa John Paul, Ikiriza Antony, Maureen Andinda. Factors Influencing Women's Choice of Place of Delivery in Ngenge Sub-county, Kween District-Uganda. Science Journal of Clinical Medicine. Vol. 9, No. 3, 2020, pp. 68-73. doi: 10.11648/j.sjcm.20200903.15

Received: February 23, 2020; Accepted: August 3, 2020; Published: September 24, 2020

\begin{abstract}
Background: Maternal and neonatal morbidity and mortality are major public health concerns in most developing countries and in under resourced settings. Increasing the proportion of babies that are delivered in health facilities is an important factor in reducing the health risks to both the mother and the baby. In Uganda's skilled birth attendance is $58 \%$ of antenatal care mothers. Objective: The study assessed factors influencing the choice of place of delivery among women of reproductive age in Ngenge Sub County, Kween District- Sebei Sub region, Eastern Uganda. Methodology: The study design was cross-sectional in which data were collected using an interviewer administered structured questionnaire and analyzed using Epi info version 7.2. Results: A total of 350 mothers were interviewed of which $82 \%$ were married. Delivery under skilled attendance was $46 \%$. Chances of delivering at the health facility decreased with increase in age $(\mathrm{p}=0.001)$, with increased parity $(\mathrm{p}=0.002)$, and increased with higher household income $(\mathrm{p}=0.011)$, and among mothers and their partners who had higher level of education ( $\mathrm{p}=0.031,0.024$ respectively). The factors which influenced delivery in the health facility included: short waiting time at the health facility before receiving health care services, good attitude of the health care workers, and adequate birth preparedness during ANC. The factors which influenced delivery elsewhere included; the far distances to the nearest health facility, low education of mothers and their partners, increased maternal age, low household income, high parity, poor decision making and high perception of the mothers about the care provided by TBAs. Conclusion: The study concludes that skilled delivery was low at $46 \%$ way-below the national target of $95 \%$. The factors statistically associated with choice of place of delivery included: waiting time at the health facility, attitude of the health care workers, birth preparedness during ANC, distance to the nearest health facility, level of education of mothers and their partners, maternal age, household income, parity of mothers, decision making, and perception of the mothers about the care provided by TBAs.
\end{abstract}

Keywords: Women's Choice, Place of Delivery, Traditional Birth Attendants

\section{Background}

Pregnancy and childbirth related complications claim lives of at least 303,000 women delivering outside the health facilities every year in developing world. The United Nations population fund (UNFPA) estimates that $90 \%$ of the global maternal deaths occur in resource limited settings $[1,2]$.

In Sub Saharan Africa, delivery in health facility is reported at $59 \%$ of mothers attending antenatal care. Consequently, the maternal mortality rate remains high at 547 deaths per 100,000 live births and in East Africa,
Rwanda records the highest skilled birth attendance at 91\% of antenatal care mothers, with the lowest being South Sudan recording skilled birth attendance of $19 \%$ of all antenatal care mothers. No wonder, Rwanda has the lowest maternal mortality of 290 deaths per 100,000 live births, and South Sudan has the highest maternal mortality rate in the region of 789 deaths per 100,000 live births [2].

WHO utilizes as one of its strategies, increasing the percentage of babies that are delivered in health facilities as an important factor in reducing the health risks to both the mother and the baby and this has become a global effort to realize the right of every woman to the best possible 
healthcare during pregnancy and childbirth. Uganda government has equipped and staffed health facilities starting from HCIII to increase on quality maternal and child healthcare $[1,2]$.

In Sebei Sub region only $25 \%$ of mothers choose to deliver at the health facilities based on a study on maternal delivery preferences and in Kween District the number of births occurring in the health facility attended by skilled health personnel remains low at $35.6 \%$ of antenatal care mothers $[2$, $10]$.

\section{Methodology}

\subsection{Study Design and Setting}

This was a household based survey that was conducted in Ngenge Sub County, selected randomly through a multistage random sampling of Kween District, a distance of $309 \mathrm{~km}$ from the capital city Kampala by road. The district was purposively selected because it contributes the highest maternal mortality in the Eastern Uganda.

\subsection{Sample Size Estimation, Sampling Procedure and Data Collection}

The sample of 350 was determined using a standard formula by Kish Leslie assuming a standard error of $5 \%$. Ngenge Sub County was selected randomly through a two stage random sampling of Kween District. A household list for each village was obtained with the aid of the LCs and they were used to randomly assign households to different research assistants during the data collection process.
Mothers who had given birth in the last one year to the study were interviewed using a structured questionnaire that contained both closed and open ended questions and in case they were absent, the research assistants had to revisit the household on other occasion.

\subsection{Data Analysis}

Data was analysed using Epi info version 7.2 for data analysis, Chi square test was used to identify the factors that influence the women's choice of place of delivery. The association between the identified factors and the choice of place of delivery was established at $p$-value $\leq 0.05$.

\subsection{Ethical Considerations}

Ethical approval was obtained from the Mountains of the Moon University, Department of Public health seeking permission to conduct the study which was presented to the officials of Kween District and Ngenge Sub County, and written informed consent was obtained from the study participants.

\section{Results}

\subsection{Demographic Characteristics}

A total of 350 respondents were surveyed in May 2017. Half of the respondents were aged 24 years below $175(50 \%)$ and $287(82 \%)$ were married. More demographic characteristics are shown in table 1 .

Table 1. Demographic Characteristics of the respondents $(n=350)$.

\begin{tabular}{lll}
\hline Factor & Frequency & Percentage \\
\hline Age (in years) & 8 & 2.3 \\
Less than 15 & 77 & 22 \\
$15-19$ & 90 & 25.7 \\
$20-24$ & 85 & 24.3 \\
$25-29$ & 59 & 16.9 \\
$30-35$ & 31 & 8.9 \\
Above 35 & & 82 \\
Marital status & 287 & 8 \\
Married & 28 & 4 \\
Single & 14 & 6 \\
Widow & 21 & 48 \\
Divorced/ Separated & & 42 \\
Household Income (Ug.Shs) & 168 & 8 \\
Less than 50,000 & 147 & 2 \\
$50,000-300,000$ & 28 & 50 \\
310,000-1,000,000 & 7 & 38 \\
More than 1,000,000 & & 4 \\
Education level of mother & 175 & 8 \\
Primary & 133 & \\
Secondary & 14 & 32 \\
Tertiary & 28 & 44 \\
None & & 6 \\
Education level of partner & 112 & \\
Primary & 154 & \\
Secondary & 21 & \\
Tertiary & 28 & \\
None & & \\
Religion & & \\
\hline
\end{tabular}




\begin{tabular}{lll}
\hline Factor & Frequency & Percentage \\
\hline Christian & 290 & 82.9 \\
Islam & 41 & 11.7 \\
Other & 19 & 5.4 \\
Occupation of mother & 120 & 34.3 \\
Farmer & 63 & 18 \\
Business woman & 107 & 30.6 \\
Housewife/Unemployed & 60 & 17.1 \\
Formal employment & & 31 \\
Distance to nearest health facility & 107 & 51 \\
Near $(\leq 5 \mathrm{~km})$ & 180 & 18 \\
Far (5-10km) & 63 & 30.6 \\
Very far $(>10 \mathrm{~km})$ & & 51.4 \\
Parity & 107 & 18 \\
One Child & 180 & \\
Two-Four & 63 & \\
More than four & & \\
\hline
\end{tabular}

Source: Field data, 2019.

\subsection{Demographic Characteristics and Choice of Place of Delivery}

The study found a significant association between choice of place of delivery and age where older mothers were more likely to deliver at home $\left(\mathrm{X}^{2}=99.361, \mathrm{p}=0.001\right)$, household income where most mothers belonging to the lower economic quintiles delivered at home $\left(X^{2}=89.60, p=0.011\right)$, distance to the health facility $\left(X^{2}=10.558, p=0.001\right)$, parity $\left(X^{2}=9.748, p=0.002\right)$, levels of education for both mother and partner respectively whereby those with secondary and above level of education were more likely to deliver at the health facility $\left(X^{2}=34.736\right.$, $p=0.013)$ and $\left(X^{2}=19.341, p=0.024\right)$ as shown in table 2 below.

Table 2. Socio-demographic factors \& association with choice of place of delivery $(N=350)$.

\begin{tabular}{|c|c|c|c|c|c|c|}
\hline \multirow{2}{*}{ Factor } & \multirow{2}{*}{ Frequency } & \multirow{2}{*}{ Percentage } & \multicolumn{2}{|c|}{ Place of delivery } & \multirow{2}{*}{$\mathbf{X} 2$} & \multirow{2}{*}{ P-value } \\
\hline & & & Home & Hospital & & \\
\hline \multicolumn{7}{|l|}{ Age (in years) } \\
\hline Less than 15 & 8 & 2 & $2(1)$ & $6(4)$ & & \\
\hline $15-19$ & 77 & 22 & $36(19)$ & $41(25)$ & & \\
\hline $20-24 * 1$ & 90 & 26 & $37(20)$ & $53(33)$ & 99.361 & 0.001 \\
\hline $25-29$ & 85 & 24 & $55(29)$ & $30(19)$ & 78.682 & 0.065 \\
\hline $30-35$ & 59 & 17 & $39(21)$ & $20(12)$ & & \\
\hline Above 35 & 31 & 9 & $20(10)$ & $11(9)$ & & \\
\hline \multicolumn{7}{|l|}{ Marital status } \\
\hline Married*1 & 287 & 82 & $150(79)$ & $137(85)$ & 0.134 & 0.604 \\
\hline Single & 28 & 8 & $16(8)$ & $12(8)$ & 0.153 & 0.985 \\
\hline Widow & 14 & 4 & $10(5)$ & $4(2)$ & & \\
\hline Divorced/ Separated & 21 & 6 & $13(8)$ & $8(5)$ & & \\
\hline \multicolumn{7}{|c|}{ Household Income (Ug.Shs) } \\
\hline Less than $50,000 * 1$ & 168 & 48 & $142(75)$ & $26(16)$ & 89.60 & 0.011 \\
\hline $50,000-300,000$ & 147 & 42 & $39(20)$ & $108(67)$ & 67.03 & 0.085 \\
\hline $310,000-1,000,000$ & 28 & 8 & $7(4)$ & 21(13) & & \\
\hline More than $1,000,000$ & 7 & 2 & $1(1)$ & $6(4)$ & & \\
\hline \multicolumn{7}{|l|}{ Education level of mother } \\
\hline Primary & 175 & 50 & $110(58)$ & $65(40)$ & 19.333 & 0.095 \\
\hline Secondary*1 & 133 & 38 & $53(28)$ & $80(50)$ & 34.736 & 0.013 \\
\hline Tertiary & 14 & 4 & $4(2)$ & $10(6)$ & & \\
\hline None & 28 & 8 & $22(12)$ & $6(4)$ & & \\
\hline \multicolumn{7}{|l|}{ Education level of partner } \\
\hline Primary & 122 & 32 & $94(50)$ & $28(17)$ & 12.650 & 0.001 \\
\hline Secondary*1 & 164 & 44 & $67(35)$ & $97(60)$ & 19.341 & 0.024 \\
\hline Tertiary & 31 & 6 & $9(5)$ & $22(14)$ & & \\
\hline None & 33 & 8 & $19(10)$ & 14(9) & & \\
\hline \multicolumn{7}{|l|}{ Religion } \\
\hline Christian*1 & 290 & 82.9 & $152(80)$ & $138(86)$ & 8.221 & 0.679 \\
\hline Islam & 41 & 11.7 & $20(11)$ & 21(13) & 5.338 & 0.934 \\
\hline Other & 19 & 5.4 & $17(9)$ & $2(1)$ & & \\
\hline \multicolumn{7}{|l|}{ Occupation of mother } \\
\hline Farmer*1 & 120 & 34.3 & $75(40)$ & $45(28)$ & 12.455 & 0.032 \\
\hline Business woman & 63 & 18 & $13(7)$ & $50(31)$ & & \\
\hline Housewife/Unemployed & 107 & 30.6 & $90(47)$ & $17(11)$ & & 0.073 \\
\hline Formal employment & 60 & 17.1 & $11(6)$ & $49(30)$ & 8.068 & \\
\hline
\end{tabular}




\begin{tabular}{llllll}
\hline Factor & \multirow{2}{*}{ Frequency } & Percentage & \multicolumn{2}{l}{ Place of delivery } & \multirow{2}{*}{ P-value } \\
& & & Home & Hospital & \\
Distance to health facility & 107 & 31 & $14(7)$ & $93(58)$ & 9.540 \\
Near $(\leq 5 \mathrm{~km})$ & 180 & 51 & $121(64)$ & $59(37)$ & 0.059 \\
Far $(5-10 \mathrm{~km}) * 1$ & 63 & 18 & $54(29)$ & $9(5)$ & \\
Very far $(>10 \mathrm{~km})$ & & & & & \\
Parity & 107 & 30.6 & $9(5)$ & $40(25)$ & \\
One Child & 180 & 51.4 & $23(12)$ & $47(29)$ & 9.001 \\
Two-Four & 63 & 18 & $157(83)$ & $74(46)$ & 0.002 \\
More than four*1 & & & & & \\
\hline
\end{tabular}

Source: Field data, 2019

* Significantly associated at $\mathrm{P}<0.05$.

\subsection{Cultural Factors on Choice of Place of Delivery}

There was significant association between decision making and choice of place of delivery $\left(\mathrm{X}^{2}=18.661, \mathrm{p}=0.001\right)$, and perceptions of mothers about the attitudes of the healthcare provider $\left(\mathrm{X}^{2}=78.063, \mathrm{p}=0.005\right)$ as shown in table 3 below.

Table 3. Cultural factors and their association with choice of place of delivery $(N=350)$.

\begin{tabular}{|c|c|c|c|c|}
\hline \multirow{2}{*}{ Factor } & \multicolumn{2}{|c|}{ Place of delivery } & \multirow[b]{2}{*}{$X^{2}$-value } & \multirow[b]{2}{*}{ P-value } \\
\hline & Home & Hospital & & \\
\hline \multicolumn{5}{|c|}{ Religious \& family beliefs } \\
\hline Yes & $7(2)$ & $3(5)$ & & \\
\hline No & $280(98)$ & $60(95)$ & 12.229 & 0.084 \\
\hline \multicolumn{5}{|c|}{ Decision making } \\
\hline By self & $80(42)$ & $90(56)$ & & \\
\hline By other party & $109(58)$ & 71(44) & 18.661 & $0.001 *$ \\
\hline \multicolumn{5}{|c|}{ Perception about healthcare provider } \\
\hline Good caring & $180(95)$ & $100(62)$ & 78.063 & $0.005 *$ \\
\hline None caring & $9(5)$ & $61(38)$ & & \\
\hline
\end{tabular}

Source: Field data, 2019

* Significantly associated at $\mathrm{p} \leq 0.05$

\subsection{Health Facility Factors on Choice of Place of Delivery}

The study found significant association between choice of place of delivery and attendance where mothers who attended four or more ANC visits delivered at the health facility $\left(X^{2}\right.$
$=35.115, p=0.001)$, attitudes of the healthcare providers $\left(X^{2}\right.$ $=5.558, p=0.002)$ and waiting time at the health facility $\left(\left(X^{2}\right.\right.$ $=22.485, p=0.001)$ as shown in table 4 below.

Table 4. Health facility factors and association with choice of place of delivery $(N=350)$.

\begin{tabular}{|c|c|c|c|c|}
\hline \multirow{2}{*}{ Factor } & \multicolumn{2}{|c|}{ Place of delivery } & \multirow{2}{*}{$X^{2}$-value } & \multirow{2}{*}{ P-valuc } \\
\hline & Home & Hospital & & \\
\hline \multicolumn{5}{|l|}{ Antenatal care attendance } \\
\hline Visit One & $4(3)$ & $3(2)$ & & \\
\hline Visit Two & $18(11)$ & $10(6)$ & & \\
\hline Visit Three & $23(14)$ & $26(16)$ & & \\
\hline Visit Four or more & $118(72)$ & $120(76)$ & 35.115 & 0.001 \\
\hline None*1 & $25(89)^{*}$ & $3(11)^{*}$ & 18.229 & 0.073 \\
\hline \multicolumn{5}{|l|}{ Attitude of the health workers } \\
\hline Welcoming & $19(10)$ & $30(19)$ & & \\
\hline Not welcoming & $170(90)$ & $131(81)$ & 5.558 & 0.002 \\
\hline \multicolumn{5}{|l|}{ Waiting time at the health facility } \\
\hline Short (Less than 30 minutes) $* 1$ & $32(17)$ & $73(45)$ & 22.485 & 0.001 \\
\hline Long ( 30 minutes to 1 hour) & $95(50)$ & $80(50)$ & 96.056 & 0.937 \\
\hline Very Long (More than 1 hour) & $62(33)$ & $8(5)$ & & \\
\hline
\end{tabular}

Source: Field data, 2019.

* Significantly associated at $\mathrm{P}<0.05$.

\section{Discussions}

Age was statistically associated with choice of place of delivery whereby most of the younger mothers delivered in the health facility compared to older mothers $\left(X^{2}=99.361\right.$, $\mathrm{p}=0.001$ ). This could be attributed to the fact that young mothers have less delivery experience and fear the risks associated with pregnancy and child birth compared to the older mothers. This is in agreement with a study conducted in Ethiopia by Yibeltal and others in 2015 who found that 
young women have lower probability of giving birth at home compared to older women, and also consistent with Envuladu and others who found that older women consist of more traditional cohorts and may resist modern healthcare services[4,8].

In this study, $69.4 \%$ of the women reported the distance to the nearest health facility to be far with significant association to the choice of place of delivery $\left(X^{2}=10.558\right.$, $\mathrm{p}=0.001)$. Distance and accessibility of services exert a dual influence in health care utilization. Long distance or inaccessibility of services can be an actual obstacle to reaching a health facility but can also be a disincentive even to trying to seek care. Distance separates patients and clients from the nearest health facility, becoming a barrier particularly in rural areas. Mothers often had to walk or improvise means of transportation to reach a health care facility. Moreover, distance was strongly adhered to other factors such as availability and cost of transport which are equally challenging in this rural setting. These findings differ from a study conducted in Kenya by John Kitui and others where $53 \%$ of deliveries took place outside the health facilities despite more than $88 \%$ of mothers living less than five kilometers from the health facility[4].

Education similarly influenced choice of place of delivery. Findings in this study show that women with higher education level of at least secondary school gave birth at a health facility compared to the uneducated women who gave birth outside the health facilities without the help of skilled birth attendance $\left(X^{2}=34.736, p=0.013\right)$. This could be attributed to the positive influence education has on society's behavior formation and change which is built from exposure to information and ideas of new trends and practices. Mothers' knowledge is an important factor in enabling them attend ANC. Education empowers the woman to make appropriate decisions concerning her own health and that of the family. This is in line with a study by Mansur and others in 2010 on the relationship between educational attainment and maternal health care utilization in Bangladesh in which education attainment of the mother predicted maternal health care utilization as educated mothers were more likely to use ANC than those without. Educated mothers also had substantial knowledge on risk factors [9].

This study found that $17.1 \%$ of the mothers had their choice of place of delivery determined by their mother-inlaws. Culturally, mother-in-laws have significant moral authority to make determinations concerning the health seeking practices of their daughter in-laws. This could also be because advice of the elder women in the house cannot be ignored and the fact that these mothers fear to disclose to any other persons. This is in agreement with Simkhada et.al in 2010 in a study conducted in Nepal who found that women have little or no power to make independent decision regarding choice of health services utilization in their marital home and are almost entirely at the mercy of their mother in law's perception of their pregnancy and delivery care needs and another keeping pregnancy as a secret by Kennedy Machira and Martin Palamuleni in Malawi [7, 11].
The study also found that (92\%) of women attended antenatal care services however, of these only $50 \%$ delivered in a health facility. This could be attributed to the fact that many of the mothers were not supported to develop an individual birth plan (IBP). Only $34.2 \%$ had a birth preparedness plan of where they intended to have their delivery. In many instances, the attendance of ANC by pregnant women is expected to be directly associated with the outcome of health facility delivery by the mother. This is so because of the assumption that pregnant mothers are counseled and educated on how to prepare an Individual Birth Plan, advised on where to deliver when the pregnancy is due and sensitized on signs of pregnancy complications among others. These findings are in line with a study on factors influencing place of delivery in Soroti, Uganda by Akinyo in 2009 where four or more antenatal visit attendance was found to be as high as $94 \%$, but deliveries in the health facility was $70.5 \%$, with the rest delivering elsewhere[6].

The study found a major disparity between antenatal care utilization and delivery in the health facilities. It is evident that $92 \%$ of mothers received antenatal care at least once during pregnancy from a skilled health provider but only $46 \%$ of these delivered under a skilled attendance. This could be attributed to a number of factors including poor quality of healthcare services, the long distances to the health facility where two thirds of the mothers indicated trekking more than $5 \mathrm{~km}$ beyond what is recommended by the Uganda national health development strategic plan 2016 - 2020 which recommends an acceptably normal walk-able distance of not more than $5 \mathrm{kms}$ for health seeking to appropriate health facility. This could also be attributed to the long waiting time at the health facility before receiving care for more than 30 minutes reported by $70 \%$ of the participants which was a disincentive to receiving institutional care, and the fact that the decision on choice of place of delivery was largely made by other party as reported by more than half $(51.4 \%)$ of the study participants whose choice of place of delivery was made by their husbands and mother-in-laws. This is also in conformity with a study in Nigeria, where home delivery was attributed to previous negative experiences during delivery at the health facilities and so mothers decided that home delivery is the better option [4].

However, the study findings show a growing preference for institutional deliveries among women in the study area when compared to the previous study on maternal delivery preferences in Sebei region by Kwagala, 2013 which revealed that only $25 \%$ of mothers delivered in the health facilities. However, when compared to the Uganda Demographic and Household Survey of 2016 [5] which indicates that $64 \%$ of the mothers in Sebei region deliver in the health facilities, the study reveals a decline in maternal preferences for institutional deliveries. This could be due to the fact that the current study focused on one district (Kween) of Sebei region while Kwagala, 2013 and UDHS, 2016 focused on the entire Sebei region. 


\section{Conclusion and Recommendations}

Health facility delivery was found to be $46 \%$, with most of the mothers delivering elsewhere. The factors that were found to be significantly associated with choice of delivery place are the far distances to the nearest health facility, education level of mothers and their partners, maternal age, household income, parity, waiting time at the health facility, attitude of the health care workers, birth preparedness during ANC, and decision making. Comparatively, among the factors found to influence choice of place of delivery, the health facility factors seem to be easily modifiable. Therefore, strategies should be put in place to develop interventions aimed at increasing and sustaining optimal level of healthcare delivery at health facilities to address the health service gaps leading to low quality of health services so as to restore confidence among the community members and increase health service utilization for antenatal care and maternal delivery services.

\section{Ethics and Consent to Participate}

Ethical approval was sought from the Department of Public Health Mountains of the Moon University Research and Ethics Committee and all participants consented in writing at the time of interview in their homes.

\section{Competing Interests}

All the authors do not have any possible conflicts of interest

\section{Authors' Contributions}

WJP authors conceived and designed the study; collected, analyzed, interpreted the data and drafted the manuscript; IA and AM critically revised the manuscript. All authors read and approved the final manuscript.

\section{Acknowledgements}

I thank study participants for providing information. Further, authors acknowledge the support of Mr. Ikiriza Antony of School of Public Health of Mountains of the Moon University for his guidance and support in producing this piece of work.

\section{List of Abbreviations}

ANC: Antenatal care

SDGs: Sustainable Development Goals

SSA: Sub Saharan Africa

TBA: Traditional Birth Attendant

UDHS: Uganda Demographic Health Survey

UNFPA: United Nations Population Fund

UNICEF: United Nations International Children's

Emergency Fund

WHO: World Health Organization

\section{References}

[1] Awoyemi T. T, Obuyelu, O. A and Opalua, H. I, (2011), Effects of Distance on Utilization of Healthcare Services in Rural Kogi State, Nigeria.

[2] Demographic E, Survey H. (2011); Central Statistical Agency, Addis Ababa Ethiopia: MEASURE DHS, ICF International Calverton, Maryland, USA. Developing Countries Give Birth?

[3] Kitui J., Lewis S., Davey G. (2013) Factors influencing place of delivery for women in Kenya: an analysis of the Kenya demographic and health survey, 2008/2009 BMC Pregnancy and Childbirth 2013, 13:40 doi: 10.1186/1471-2393-13-40.

[4] Envuladu E, Agbo H, Lassa S, Kigbu J, Zoakah A. 2013. Factors determining the choice of a place of delivery among pregnant women in Russia village of Jos North, Nigeria: achieving the MDGs 4 and 5. International Journal of Medicine and Biomedical Research 2: 23-7.

[5] Uganda Bureau of Statistics (UBOS) and ICF. 2017. Uganda Demographic and Health Survey 2016: Key Indicators Report. Kampala, Uganda: UBOS, and Rockville, Maryland, USA: UBOS and ICF.

[6] Anne Rita Akinyo 2009. Factors influencing mother's choice of place of delivery in Soroti District, Uganda accessed from http://makir.mak.ac.ug/bitstream/handle/10570/2528/Ak inyo-COBAMS-Master.pdf; sequence $=1$

[7] Acharya, D. R., Bell, J. S., Simkhada, P. et al. 2010. Women's autonomy in household decision-making: a demographic study in Nepal. Reprod Health 7, 15 (2010). https://doi.org/10.1186/1742-4755-7-15

[8] Di Renzo, Gian Carlo, Yebekaw, Yibeltal, James Mashalla, Yohana, Thupayagale-Tshweneagae, Gloria, 2015. Factors Influencing Women's Preferences for Places to Give Birth in Addis Ababa, Ethiopia. Obstetrics and Gynecology International, Hindawi Publishing Corporation. DOI; https://doi.org/10.1155/2015/439748

[9] Mansur, Abu \& Akter, Aysha \& Mazumdar, Towhidul \& Rashid, Rumana \& Asaduzzaman, Mohammad \& Fatema, Babry \& Juliana, Farha \& Mannan, Abdul \& Islam, Mohammad \& Islam, Mohammod. (2017). Assessment of Antenatal Care (ANC) and Demography Parameters on Pregnant Women in Bangladesh. IOSR Journal of Nursing and Health Science (IOSR_JNHS). 06. 37-44. 10.9790/1959-0603083744.

[10] Kwagala Betty. Birthing choices among the Sabiny of Uganda. Cult Health Sex. 2013; 15 Suppl 3: S401-S414. doi:10.1080/13691058.2013.799232

[11] Machira K, Palamuleni M. Women's perspectives on quality of maternal health care services in Malawi. Int $J$ Womens Health. 2018;10:25-34 https://doi.org/10.2147/IJWH.S144426 